\title{
HOMENAJE AL DR. ANTONIO GÓMEZ ROBLEDO
}

BERNABÉ NAVARRO B.

INSTITUTO DE INVESTIGACIONES FLÓSOFICAS UNIVERSIDAD NACIONAL AUTÓNOMA DE MÉXICO

En el anuncio de la presentación de la Ética eudemia de Aristóteles, traducida por don Antonio Gómez Robledo, se dice que el acto se organiza. "En homenaje" a él, es decir, al insigne humanista clásico que fue. Independientemente del sentido que quiso dar el redactor del texto al poner en relación el "homenaje" con la última labor y publicación del maestro en el área de filosofía griega clásica, yo me permito disentir un tanto, es decir, en parte, porque quiero extender, con derecho sin duda, el muy merecido homenaje que le celebra el Instituto a que perteneció, extender, digo, a toda la obra que realizó en ese campo, ya consistiera en traducciones, ya la formaran, sobre todo, obras originales.

Entre estas últimas se destaca con mucho, a mi juicio, la monumental obra: Platón. Los seis grandes temas de su filosofía, con la que penetra en la esencia misma del pensamiento platónico y la despliega ante el lector con lucidez, claridad y elegancia. Antes de ocuparse de Platón, había hecho objeto de su estudio y admiración al maestro de éste en la obra Sócrates y el socratismo, donde ensalza, casi con fervor, el espíritu inmarcesible de aquel hombre sublime, así como la trascendencia para todos los tiempos de su ideal moral y educativo. Junto a estas obras menciono su Meditación sobre la justicia, donde los capítulos fundamentales se dedican a Platón y a Aristóteles; así como su Ensayo sobre las virtudes intelectuales, que, como se ve por el título, tiene por propósito hacer un panegírico de la doctrina aristotélica respectiva, señalándola como centro y base de la más elevada vida del espíritu.

Las traducciones son conocidas y empleadas por todos $-\mathrm{y}$ reconocidas en su valor y función- en el ámbito de la lengua española. De Aristóteles la Ética nicomáquea, la Política y la Ética eudemia; de Platón, la República; de Marco Aurelio, Pensamientos. Pero, al pensar en las traducciones, no debe tomarse en cuenta, simplemente, la labor de traducir, valiosa en sí, sino que debe atenderse a las extensas introducciones, donde, entre muchas cosas, se precisa el meollo doctrinal y se encarecen el mensaje y la trascendencia de las enseñanzas contenidas en ellas. 
Aunque todas estas obras de nuestro recordado colega, ahora desaparecido, son bien conocidas en general, he creido conveniente recordarlas ahora en este homenaje, tanto para admiración de su inmensa labor intelectual, como para ejemplo y modelo de algunos, como el que habla, en el área de la filosofía clásica griega, y de todos, en el campo de sus propias investigaciones filosóficas.

La desaparición física de don Antonio y la imposibilidad de que continuara él su variada y fecunda actividad intelectual, ha hecho posible para mí, como quizá también para muchos de los presentes, desplegar una visión de conjunto de toda la obra realizada y publicada por él, visión total, por lo dicho al principio, a menos que póstumamente se dieran a conocer al público otros escritos, redactados desde antes o quizá después de la aparición de la obra que aquí se presenta. Hasta el momento, que se sepa en nuestro Instituto, los familiares y herederos no han manifestado nada al respecto. Sin embargo, yo personalmente no creo que su incansable pluma, tan ávida de manifestar a todos el meollo y sentido de los temas que le interesaban y de los problemas que le preocupaban, haya quedado inmóvil en el último momento.

Por breves pláticas y cambios de impresiones acerca de asuntos clásicos griegos, supe yo que tenía en mente discurrir sobre varios problemas, en especial filosóficos, como el concepto de Dios en Aristóteles y Platón, o también filológicos, como el de la pronunciación del griego clásico, que solía plantearme con frecuencia, pues le constaba que yo sostenía la pronunciación llamada "erasmiana", mientras que él defendía vigorosamente, y con ciertas bases, que aquél debía pronunciarse conforme a la del griego moderno. Acerca de ese problema, le mostré en una ocasión el texto de un tratado de Erasmo de Rotterdam, Acerca de la correcta pronunciación del griego clásico; pero como estaba escrito con caracteres muy pequeños de una vieja edición de las Obras completas de aquel gran humanista, me pidió que le transcribiera el texto a máquina y que por favor se lo tradujera - estaba escrito en latín-, obviamente no porque él ignorara esta lengua, sino porque no disponía de tiempo para hacerlo. Debo reconocer aquí con cierta pena que no pude llevar a cabo su petición, y quedó convencido de que su posición era la correcta.

Ya que en este preámbulo - antes de entrar al tema de la presentaciónno he creído fuera de propósito hablar un poco de mi relación personal intelectual con él, deseo añadir públicamente mi reconocimiento y gratitud por sus atenciones al atribuirme méritos y conocimientos de los que carezco, al aceptar con sinceridad mis críticas en reseñas que hice de sus obras y al distinguirme con el obsequio de recuerdos traídos de Grecia al regreso de su amada y admirada segunda patria, ila Grecia eterna de Aristóteles y de Platón! 
Al principio de mis palabras, dejé trunca la idea de ofrecer una visión de conjunto de la obra de don Antonio, y quiero completarla antes de referirme a su Ética eudemia; digo "su" porque el traductor-intérprete, sobre todo como él lo entendía, es con derecho el segundo autor. De algún modo se agiganta su figura frente a nosotros, al presentársenos de golpe, por el hecho de su desaparición, el total de sus diversas obras, según sus varios tipos y en las diferentes áreas. En especial, a mí me tocaría recordar las del área clásica griega, que he hecho brevemente ya. Pero no debo olvidar su labor en otra área, que también era de ambos, suya y mía, o sea, la filosofía novohispana, en la que hizo dos grandes aportaciones al conocimiento de la obra de fray Alonso de la Veracruz, sobre la que publicó: El magisterio filosófico de fray Alonso de la Veracruz (Porrúa) y la traducción de gran parte de la obra jurídico-política de aquel ilustre faile agustino, recién descubierta en manuscrito: la Relectio de dominio infidelium et iusto bello, traducción que se publicó en dos antologías editadas en la ciudad de Morelia.

Voy a terminar por la parte por la que debí haber empezado, o sea, por la apreciación y juicio acerca de la obra que es objeto especial de este homenaje; por ello y por cierta brevedad en la formulación de mis puntos de vista, pido disculpas, encareciendo que, en razón de mi amistad y contacto personales - según advirtió el oyente en la descripción de algunos detalles-, antes me dejé llevar un poco por la emotividad más que por la serena visión del intelecto.

Al leer la introducción de la obra me saltó a la vista la justa brevedad de la misma, en comparación con la amplitud mayor de las introducciones a la Ética nicomáquea, por ejemplo, y a la República. Pero esa brevedad está acorde con la necesidad, es decir, no responde simplemente al propósito de ser breve, sino a la forma concisa en que discurrió y formuló los temas y puntos necesarios. Entre éstos hay aspectos y problemas filológicos que trata de aclarar y resolver, así como cuestiones doctrinales que trata de precisar y explicar con referencia a doctrinas afines, de la época, por ejemplo de Platón, o posteriores, de Tomás de Aquino. En lo filológico, sus fundamentos son sólidos, pues se trata de los hallazgos de Jaeger, von Arnim y Düring. Problemas filológicos deslindados son: la preferencia por la Ética eudemia frente a la Gran ética; la juiciosa inclinación por los títulos A Nicómaco y A Eudemo, frente a los usuales: Nicomáquea y Eudemia; la presencia de libros comunes a ambos tratados de ética y la duda sobre si éstos fueron redactados inicialmente para una obra o para otra, la precisión del concepto acuñado por Aristóteles de la $\kappa \alpha \lambda o \kappa \dot{\alpha} \gamma \alpha \theta i \alpha$, etc. Sobre cuestiones doctrinales, me parece importante señalar éstas: en primer lugar la llamada de atención sobre la elevada espiritualidad y la presencia e influencia de Dios o de la divinidad en la concepción general de la Ética eudemia; en segundo lugar, pero con el mismo sentido o finalidad que el punto anterior, la estrecha relación que establece él entre el Protréptico del mismo Aristóteles, que es 
un Panegírico a la vida del espíritu, y la Ética eudemia. La precisión sobre la $\phi \rho o ́ v \eta \sigma \iota \varsigma$ en los libros comunes y especialmente en la Eudemia. Acerca del tema de la traducción, antes de referirme a la labor misma interpretativa de don Antonio, debo notar que en la introducción hay un juicio suyo sobre los tipos de esa labor, en el que censura, por ser totalmente inadecuada, la traducción literal o de calca, que es "usual", según él, en la Colección Bilingüe de la Universidad. Dejo a consideración si su juicio sobre este último hecho era correcto o no. Acerca del tipo y valor de la traducción de don Antonio en esta obra, siento el deber de manifestar, con toda sinceridad, que en las diversas y variadas pruebas que hice, encontré una correspondencia extraordinaria -que no encontraba en otras de sus traducciones- entre el texto griego y su texto castellano, no sólo en cuanto al fondo sino también en cuanto a la forma, pero lejos del tipo de traducción que él rechazara. Tal correspondencia yo la evalúo como algo muy positivo y valioso, pues me parece que sigue la línea que suele tenerse ahora como científica. 